\title{
COVID-19 e Acidente Vascular Cerebral COVID-19 and Stroke
}

\author{
José M Ferro ${ }^{1,2, *}$ \\ 1-Serviço de Neurologia, Centro Hospitalar e Universitário de Lisboa Norte - Hospital de Santa Maria, Lisboa, Portugal. \\ 2-Faculdade de Medicina da Universidade de Lisboa, Lisboa, Portugal.
}

A pandemia COVID-19 coloca a todos um enorme desafio de resiliência, adaptação e principalmente solidariedade. Infelizmente, a emergência desta temível infeção não fez reduzir ou desparecer as outras doenças, nomeadamente as situações agudas, também potencialmente fatais, mas sobretudo incapacitantes, de que são exemplo os acidentes vasculares cerebrais (AVC).

Não há qualquer prova que o novo coronavírus cause AVC, ou que os sobreviventes de um AVC tenham maior risco de infeção, exceto se estiverem muito debilitados ou tiverem outras doenças que afetem a imunidade.

Importante é não interromper a medicação habitual, em particular a destinada a controlar a hipertensão arterial. Não se recomenda a paragem de anti-hipertensores das classes IECA (inibidores da enzima de conversão da angiotensina) ou ARA (antagonistas de receptores da angiotensina), sob o pretexto de que poderiam aumentar o risco de infeção ou a sua gravidade, pois não só não há confirmação dessa hipótese, como existem até alguns trabalhos científicos sugerindo o contrário.

No caso de AVC agudo ou suspeita dele, deve ser contactado o Instituto Nacional de Emergência Médica (INEM) através do número I 12, como está preconizado, pois as Vias Verdes e a trombectomia continuam a funcionar regularmente. Poderá vir a ser necessário redesenhar as redes de referenciação para reduzir as transferências entre hospitais, concentrar as trombectomias em hospitais "sem COVID", se tal ainda for possível e recorrer menos à anestesia geral para efetuar este tratamento.

Para as pessoas sobreviventes de um AVC que faziam reabilitação regular ou apenas marcha diária, será necessário adaptarem-se às circunstâncias presentes. A reabilitação à distância com transmissão de imagem via telemóvel ou computador, ou simplesmente através de instruções fornecidas via telefone pelo terapeuta são boas alternativas. Podem-se e devem-se fazer exercícios em casa sem necessidade de sair à rua, tais como subir escadas, fazer movimentos dos braços imitando o boxe ou exercícios de reforço muscular, principalmente dos membros inferiores.

Se o aumento do número de casos graves necessitando de cuidados intensivos vier a superar as disponibilidades existentes, vão-se colocar complexos e terríveis problemas éticos. O rateio de recursos em situação de escassez deverá considerar os resultados em saúde expectáveis devidos à intervenção intensiva, não só a curto prazo, mas principalmente a longo prazo e ainda a expectativa que todos temos de poder percorrer as diferentes fases da vida, o que alguns de nós já fizemos e outros ainda não.

Mais uma vez a Humanidade, a Europa e Portugal irão sobreviver.

\section{Responsabilidades Éticas}

Conflitos de Interesse: Os autores declaram não possuir conflitos de interesse.

Suporte Financeiro: O presente trabalho não foi suportado por nenhum subsídio ou bolsa.

Proveniência e Revisão por Pares: Não comissionado; revisão externa por pares.
Informações/Informations: Artigo de perspetiva, publicado em Sinapse, Volume 20, Número 2, abril-junho 2020. Versão eletrónica em www.sinapse.pt

Perspective article, published

in Sinapse, Volume 20, Number

2, april-june 2020. Electronic

version in www.sinapse.pt

(C) Autor (es) (ou seu (s)

empregador (es)) 2020.

Reutilização permitida de

acordo com CC BY-NC.

Nenhuma reutilização

comercial.

(c) Author(s) (or their employer(s)) 2020. Re-use permitted under CC BY-NC.

No commercial re-use.

Palavras-chave:

Acidente Vascular Cerebral; COVID-19.

Keywords:

COVID-19;

Stroke.

*Autor Correspondente / Corresponding Author: José M Ferro

Serviço de Neurologia

Centro Hospitalar e

Universitário de Lisboa Norte Hospital de Santa Maria

Avenida Prof. Egas Moniz 1649-028 Lisboa, Portugal jmferro@medicina.ulisboa.pt

Recebido / Received: 2020-05-20 Aceite / Accepted: 2020-06-02 Publicado / Published: 2020-07-13

DOI: https://doi.org/10.46531/ sinapse/AR/COVID19/FerroJ/2020

\section{Ethical Disclosures}

Conflicts of Interest: The authors have no conflicts of interest to declare.

Financial Support: This work has not received any contribution grant or scholarship.

Provenance and Peer Review: Not commissioned; externally peer reviewed. 